\title{
Swiss Practice Recommendations for the Management of Hidradenitis Suppurativa/Acne Inversa
}

\author{
Robert E. Hunger ${ }^{a} \quad$ Emanuel Laffitte $^{b}$ Severin Läuchlic Carlo Mainetti ${ }^{d}$ \\ Michael Mühlstädt ${ }^{b}$ Peter Schiller ${ }^{\mathrm{e}}$ Anne-Karine Lapointe ${ }^{\mathrm{g}}$ \\ Pascale Meschberger ${ }^{f} \quad$ Alexander A. Navarini ${ }^{c}$ \\ ${ }^{a}$ Department of Dermatology, Inselspital, Bern University Hospital, University of Bern, Bern, ${ }^{\mathrm{b}}$ Division of \\ Dermatology and Venereology, Geneva University Hospitals, Geneva, 'Department of Dermatology, Zurich \\ University Hospital, Zurich, dDepartment of Dermatology, Ospedale Regionale Bellinzona e Valli, Bellinzona, \\ e Private Practice, and ${ }^{\mathrm{f}}$ Department of Surgery, Kantonsspital Baselland, Liestal, and ${ }^{9}$ Private Practice, \\ Lausanne, Switzerland
}

\section{Keywords}

Hidradenitis suppurativa · Acne inversa - Pathogenesis .

Diagnosis $\cdot$ Treatment $\cdot$ Recommendations

\begin{abstract}
Hidradenitis suppurativa (HS) is a painful, inflammatory, debilitating skin disease with a chronic intermittent course. The central pathogenetic event seems to be the occlusion of the hair follicle. HS has a 1-year prevalence of about $1 \%$. It typically presents after puberty with painful, deep-seated, inflamed lesions in the apocrine gland-bearing areas of the body: most commonly the axillae, inguinal, and anogenital regions. HS has a high negative impact on patients' quality of life even in patients with only limited disease burden, and the diagnosis of HS is often made with a long diagnostic delay. In this practical short version we present diagnostic and therapeutic recommendations which are based on a systematic literature search as well as an informal expert consensus of Swiss dermatologists and dermatosurgeons.
\end{abstract}

ㄷ) 2017 S. Karger AG, Basel (c) 2017 S. Karger AG, Basel

\section{KARGER}

E-Mail karger@karger.com

www.karger.com/drm

\section{Description of the Disease and Epidemiology}

Hidradenitis suppurativa (HS), also called "acne inversa" or "maladie de Verneuil," is a painful, inflammatory, debilitating skin disease with a chronic intermittent course. It typically presents after puberty with painful, deep-seated, inflamed lesions in the apocrine glandbearing areas of the body: most commonly the axillae, inguinal and anogenital regions [1]. Population-based studies in European countries suggest a 1-year prevalence of HS of about $1 \%$ in the general population, with estimates ranging from 0.1 to $4 \%$ globally. HS commonly presents after puberty, with the average age of onset between 21 and 23 years of age, and is more common in women, with a female to male ratio between $2: 1$ and 5:1 $[2,3]$. Associations have also been reported with other inflammatory diseases, such as inflammatory bowel disease [4], pyoderma gangrenosum [5], and polycystic ovary syndrome [6].

The exact pathogenetic mechanism of HS remains unclear. Potential causes are related to genetic, environmen-

Robert E. Hunger, MD, PhD

Department of Dermatology, Inselspital

Freiburgstrasse 34

CH-3010 Bern (Switzerland)

E-Mail robert.hunger@insel.ch 
Table 1. Typical anatomical locations of lesions in hidradenitis suppurativa (HS) as described by Canoui-Poitrine et al. [17]

\begin{tabular}{lcrr}
\hline & $\begin{array}{l}\text { Male, } \\
n(\%)\end{array}$ & \multicolumn{1}{l}{$\begin{array}{l}\text { Female, } \\
n(\%)\end{array}$} & $p$ \\
\hline Axillae & $55(78.6)$ & $154(66.7)$ & 0.06 \\
Breast & $1(1.4)$ & $52(22.5)$ & $<0.001$ \\
Inguinofemoral & $54(77.1)$ & $216(93.5)$ & $<0.001$ \\
Buttocks & $28(40.0)$ & $54(23.4)$ & 0.006 \\
Perineal/perianal & $36(51.4)$ & $76(32.9)$ & 0.005 \\
\hline
\end{tabular}

HS patients: $n=302$ (232 female, 70 male).

tal, endocrine, and microbiological factors. For example, HS can sometimes follow an autosomal dominant pattern of inheritance $[7,8]$, and a total of $35-40 \%$ of patients report a family history of the disease. Several studies have pointed to higher than average smoking rates among HS patients (70-90\%), and the severity and course of HS are correlated with body mass index. Due to its typical onset during puberty, an endocrine component has been suggested [9]. Finally, with regards to a possible microbial cause, a number of bacteria have been isolated from HS lesions. However, it is unclear whether bacteria are causal to disease pathogenesis or secondary, and hence infection is unlikely to be a primary causative factor [10]. Based on histopathological examination of HS biopsies, it is generally proposed that HS is initiated due to occlusion of the terminal hair follicle in response to hyperkeratinization, leading to nodule or cyst formation, and eventually a ruptured follicular epithelium, resulting in chronic inflammation with sinus and fistula formation and extensive dermal scarring [10-14].

\section{Clinical Presentation and Diagnosis}

HS is characterized by recurrent inflammation occurring more than 2-3 times in the last 6 months in the inverse regions of the body, presenting with nodules, sinus tracts and/or scarring [15]. The disease is most frequently localized in the axillary and inguinofemoral regions. The typical areas of involvement in males and females and their prevalence are listed in Table $1[16,17]$. In some cases atypical localizations on the ears, chest, and back are observed [18].

The diagnosis of HS is usually made by clinical examination, and in most cases skin biopsies are not required. However, they may be useful to rule out a differential di- agnosis with a gram-positive bacterial cause (e.g., furuncle or carbuncle). The diagnostic criteria are summarized in Table 2 and rely on the 3 main features of HS as previously reported [19]:

1. Typical anatomical location: axillae and inguinocrural regions - symmetrical lesions suggest systemic disease versus local infection.

2. Relapses and chronicity.

3. Typical lesions: deep-seated nodules (blind boils), comedones, and/or fibrosis.

While there is no consensus among the outcome measures used for HS, the most widely used disease activity scores are the Hurley staging and the Sartorius scoring system [20]. Hurley scoring is usually assigned to 3 stages:

Stage I: abscess formation, single or multiple, without sinus tracts and cicatrization.

Stage II: recurrent abscesses with tract formation and cicatrization, single or multiple, with widely separated lesions.

Stage III: diffuse or near-diffuse involvement, or multiple interconnected tracts and abscesses across the entire area.

Hurley stage I disease is most common (65\% of cases), followed by stage II ( $31 \%$ of cases) and stage III ( $4 \%$ of cases) [20].

The Sartorius score is a dynamic scoring system created by Sartorius et al. [21, 22] and later modified. Individual nodules and fistulas are counted, allowing a dynamic measurement of the clinical disease severity.

The diagnosis of HS is complicated due to the substantial variability in its course, making treatment challenging and resulting in a wide heterogeneity in response to treatment. It has been proposed that this might be due to undetected clinical subtypes of the disease. However, these subtypes have not yet been associated with distinct pathogenic mechanisms or differential responses to therapy [10]. Thus, future research will be required to untangle these differences in an effort to optimize treatment.

\section{Course and Burden of Disease}

HS is a chronic relapsing disease. If not treated adequately it may lead to serious complications such as bacterial infections, fistula formation, contractures and limb mobility limitations, squamous cell carcinoma, depression, anemia, malaise, and social impairment [23]. Indeed, it has been reported to prevent patients from working during disease flares [24], and the purulent discharge can produce an odor and stain clothing, resulting in social
114

Dermatology 2017;233:113-119

DOI: $10.1159 / 000477459$
Hunger et al. 
stigma [25]. Scarring can also cause considerable disability [20]. A recent study showed that the effect of HS on the Dermatology Life Quality Index (DLQI) was $5.77 \pm$ 4.59 (mean \pm SD) for patients with Hurley stage I disease, $13.1 \pm 6.41$ for patients with Hurley II, and $20.4 \pm 6.67$ for patients with Hurley III. This is very high compared to a wide spectrum of other dermatological diseases [26]. For example, moderate to severe psoriasis has a mean DLQI reported at 12-13 [27].

Among patient-reported signs and symptoms, pain was reported by $85 \%$ of individuals with HS to be the most bothersome, followed by swelling/inflammation (20\%) and sensitivity/tenderness (10\%) [28].

In addition to effects on quality of life, there is also a long diagnostic delay associated with HS. In one prospective survey study, the average patient delay in seeing a physician was $2.5 \pm 5.0$ years for individuals with HS compared to $1.0 \pm 4.3$ years for individuals with psoriasis. The diagnostic delay was $7.2 \pm 8.7$ years in HS versus $1.6 \pm 4.8$ years in psoriasis. Furthermore, individuals with HS typically see many more physicians than psoriasis patients prior to receiving their diagnosis [29].

\section{Risk Factors and Comorbidities}

Among all risk factors for HS studied to date, the strongest correlation among biological factors is obesity, while the strongest environmental association is with smoking. Revuz et al. [2] found an odds ratio (OR) of 4.42 for obesity (BMI $>30)$ and 12.55 for smoking compared to healthy controls. Another study by Miller et al. [30] found an OR of 6.38 for obesity. In line with this, individuals with diabetes mellitus $(\mathrm{OR}=5.74)$ and metabolic syndrome $(\mathrm{OR}=3.89)$ also have a strong positive association with HS [30]. Individuals with HS also suffer from a significantly higher rate of cardiovascular risk factors compared to healthy controls [31].

With respect to disease progression, 5 risk factors were associated with an increased risk of progression from Hurley stage I to stage II or III in a retrospective study of 846 Dutch individuals with HS. These included male gender, disease duration, BMI, smoking pack-years, and lesion location (with axillary, inguinal, and mammary lesions having the highest OR) [32].

In addition, mechanical irritation and friction may also trigger HS $[33,34]$, and the co-occurrence of HS with polycystic ovary syndrome, Crohn disease [35], and depression is statistically significant [36].

Clinical Practice Recommendations for

Hidradenitis Suppurativa
Table 2. Diagnostic criteria for hidradenitis suppurativa (HS)

Primary positive diagnostic criteria

History

Recurrent painful suppurating lesions more than

$2-3$ times in the last 6 months

Involvement of:

Axilla

Inguinofemoral area

Buttocks

Breast in women

Perineal/perianal area

Presence of:

Nodules (inflamed or noninflamed)

Sinus tracts (inflamed or noninflamed)

Abscesses, scaring

Follicular occlusion (comedones, fistula comedones)

\begin{tabular}{l} 
Secondary positive diagnostic criteria \\
History \\
Family history of HS \\
Microbiology \\
$\quad$ Negative swab \\
Presence of normal skin microbiota \\
\hline
\end{tabular}

\section{Treatment Options}

Because smoking and obesity show the strongest correlation with disease severity [2], there is a general consensus that individuals with HS be advised and supported in the cessation of smoking and in reducing their body weight. Furthermore, loose-fitting clothing in order to avoid mechanical stress and friction is recommended. HS has a strongly negative impact on quality of life, including depression and problems with social integration. Although there are no studies proving efficacy on HS disease course, psychosocial support measures should be considered.

Clinical practice recommendations for medical treatment are summarized in Figure 1. To avoid bacterial superinfections and reduce inflammation, maceration and/ or topical disinfectants (e.g., triclosan, ammonium bituminosulfonate) or topical antibiotics (e.g., clindamycin solution [37]) are suggested. Inflamed nodules may be injected with intralesional steroids. If topical agents are not sufficient, systemic antibiotics are typically given. Doxycycline (50-200 mg daily for 3-6 months) or rifampicin combined with clindamycin (each $300 \mathrm{mg}$ twice daily [38]) for up to 3 months are suggested. Zinc gluconate $(3 \times 30 \mathrm{mg}$ daily $)$ may be added in combination. If antibiotics are not sufficient or no longer effective, the

Dermatology 2017;233:113-119 115 


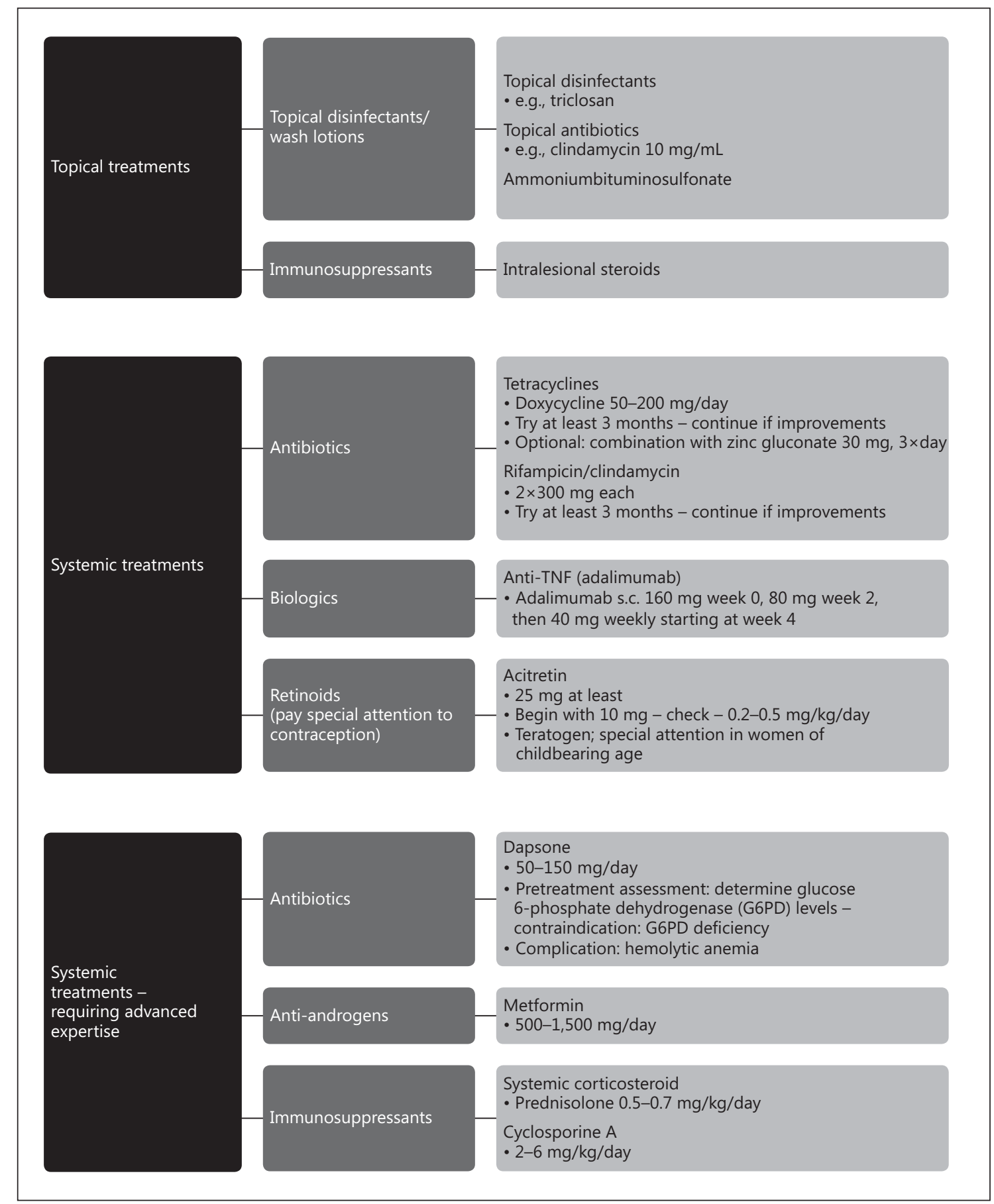

Fig. 1. Medical treatment options for hidradenitis suppurativa in Switzerland.

Swissmedic-approved dose of adalimumab should be considered (160 mg at week $1,80 \mathrm{mg}$ at week 2 , and thereafter $40 \mathrm{mg}$ weekly) [39]. Alternatively, a recent study showed improvements with systemic acitretin at a dosage of $0.2-0.5 \mathrm{mg} / \mathrm{kg}$ per day [40]. Many other agents may be used in patients with refractory disease; these include dapsone (50-150 mg daily), metformin, systemic steroids, or cyclosporine A.

Concerning surgical treatment, patients need to know about the increased rate of recurring disease in order to 


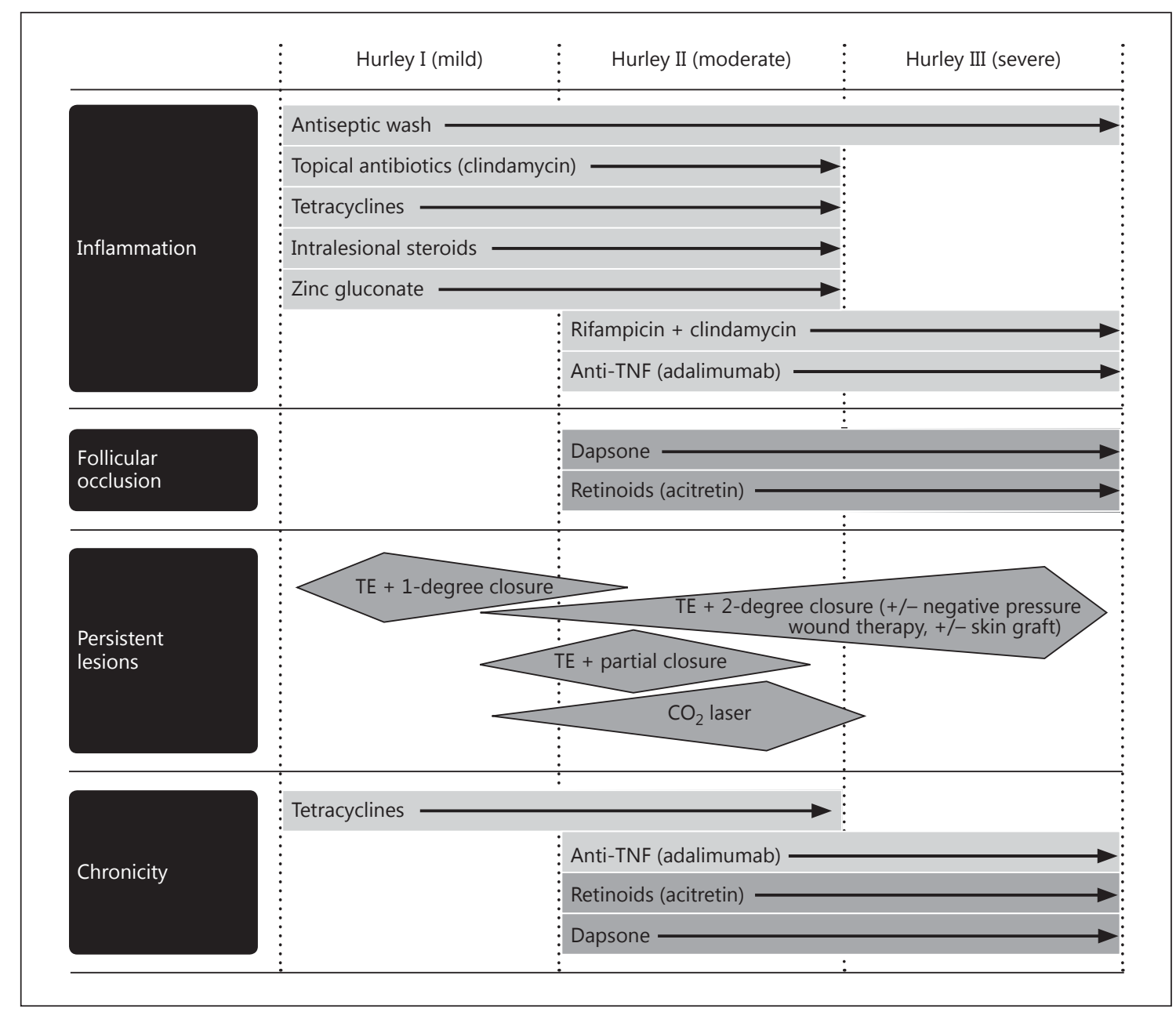

Fig. 2. Swiss expert panel treatment algorithm for hidradenitis suppurativa (HS). Avoid trigger factors: smoking, mechanical friction, weight, and shaving. Therapies for our algorithm were selected on the basis of established clinical efficacy, tolerability, and potential for adverse effects. Disease progression should be evaluated every 3 months, and for patients demonstrating inadequate disease control, progression through therapies should be followed.

make an informed consent. Local excision of single lesions is only recommended in localized, well-circumscribed cases of Hurley I and II [1]. In all other cases, wide scalpel or $\mathrm{CO}_{2}$ laser excision of the skin, including parts of the fatty tissue of the whole area affected (axilla, inguinal area, buttocks, etc.), should be considered [1]. We recommend healing by secondary intention with or without partial closure and with or without negative pressure-assisted healing. The exact surgical treatment plan is as individual as in conventional therapy and needs to be elucidated in cooperation with the patient. Physiotherapy is crucial until the complete healing of the wound.

Clinical Practice Recommendations for Hidradenitis Suppurativa
Adalimumab therapy is the only approved medication to treat active moderate to severe HS (acne inversa) in adult patients with an inadequate response to a systematic antibiotic therapy and the only therapy with evidence level A. Despite there not being any published evidence on combination therapy for HS, this may need to be considered based on disease course. TE, total excision.

The treatment algorithm based on disease-specific pathology is given in Figure 2. This algorithm recommends various treatment options based on both Hurley staging and disease-specific features: inflammatory burden, follicular occlusion, persistency of lesions, and the chronic intermittent course of the disease. Indeed, treatment options for the inflammatory features of this disease versus the noninflammatory features have also been highlighted recently by others [41-43]. Our algorithm shares similarities with these, but provides more details on therapeutic options based on further classification of HS diseasespecific pathology. 
As all nonsurgical options in HS very often lead to a nonsatisfactory result, surgical intervention is quite common and required in many cases. However, there is a lack of clinical studies examining how medical treatment and surgery should be combined, or how combination therapies should be used in general. We expect that these clinical questions will be addressed with ongoing clinical studies in the near future, allowing clinicians to reliably control all types and stages of HS.

\section{Key Message}

Hidradenitis suppurativa is one of the most neglected chronic inflammatory skin diseases.

\section{Disclosure Statement}

All of the experts prescribe all available drugs for HS and received honoraria from one or more AbbVie advisory boards, the producer of adalimumab (Humira $\left.{ }^{\circledR}\right)$. R.E.H., A.A.N., and E.L. were investigators of HS clinical trials sponsored by AbbVie. The pharma company had no influence on the content of this work.

\section{References}

1 Zouboulis CC, Bechara FG, Fritz K, Kurzen $\mathrm{H}$, Liakou AI, Marsch WC, et al: S1 guideline for the treatment of hidradenitis suppurativa/ acne inversa (number ICD-10 L73.2) (in German). J Dtsch Dermatol Ges 2012;10(suppl 5):S1-S31.

2 Revuz JE, Canoui-Poitrine F, Wolkenstein P, Viallette C, Gabison G, Pouget F, et al: Prevalence and factors associated with hidradenitis suppurativa: results from two case-control studies. J Am Acad Dermatol 2008;59:596601.

3 Jemec GB, Heidenheim M, Nielsen NH: The prevalence of hidradenitis suppurativa and its potential precursor lesions. J Am Acad Dermatol 1996;35:191-194.

4 van der Zee HH, van der Woude CJ, Florencia EF, Prens EP: Hidradenitis suppurativa and inflammatory bowel disease: are they associated? Results of a pilot study. Br J Dermatol 2010;162:195-197.

5 Hsiao JL, Antaya RJ, Berger T, Maurer T, Shinkai K, Leslie KS: Hidradenitis suppurativa and concomitant pyoderma gangrenosum: a case series and literature review. Arch Dermatol 2010;146:1265-1270.

6 Kraft JN, Searles GE: Hidradenitis suppurativa in 64 female patients: retrospective study comparing oral antibiotics and antiandrogen therapy. J Cutan Med Surg 2007;11:125-131.

7 Fitzsimmons JS, Guilbert PR: A family study of hidradenitis suppurativa. J Med Genet 1985;22:367-373.

8 Fitzsimmons JS, Guilbert PR, Fitzsimmons EM: Evidence of genetic factors in hidradenitis suppurativa. Br J Dermatol 1985;113:1-8.

9 von der Werth JM, Williams HC: The natural history of hidradenitis suppurativa. J Eur Acad Dermatol Venereol 2000;14:389-392.

10 Woodruff CM, Charlie AM, Leslie KS: Hidradenitis suppurativa: a guide for the practicing physician. Mayo Clin Proc 2015;90: 1679-1693.
11 Hunger RE, Surovy AM, Hassan AS, Braathen LR, Yawalkar N: Toll-like receptor 2 is highly expressed in lesions of acne inversa and colocalizes with C-type lectin receptor. Br J Dermatol 2008; 158:691-697.

12 Jemec GB, Hansen U: Histology of hidradenitis suppurativa. J Am Acad Dermatol 1996;34: 994-999.

13 Schlapbach C, Hanni T, Yawalkar N, Hunger RE: Expression of the IL-23/Th17 pathway in lesions of hidradenitis suppurativa. J Am Acad Dermatol 2011;65:790-798.

14 von Laffert M, Helmbold P, Wohlrab J, Fiedler E, Stadie V, Marsch WC: Hidradenitis suppurativa (acne inversa): early inflammatory events at terminal follicles and at interfollicular epidermis. Exp Dermatol 2010;19: 533-537.

15 Esmann S, Jemec GB: Psychosocial impact of hidradenitis suppurativa: a qualitative study. Acta Derm Venereol 2011;91:328-332.

16 Canoui-Poitrine F, Le Thuaut A, Revuz JE, Viallette C, Gabison G, Poli F, et al: Identification of three hidradenitis suppurativa phenotypes: latent class analysis of a cross-sectional study. J Invest Dermatol 2013;133:15061511.

17 Canoui-Poitrine F, Revuz JE, Wolkenstein P, Viallette C, Gabison G, Pouget F, et al: Clinical characteristics of a series of 302 French patients with hidradenitis suppurativa, with an analysis of factors associated with disease severity. J Am Acad Dermatol 2009;61:51-57.

18 Poli F, Wolkenstein P, Revuz J: Back and face involvement in hidradenitis suppurativa. Dermatology 2010;221:137-141.

19 Zouboulis CC, Del Marmol V, Mrowietz U, Prens EP, Tzellos T, Jemec GB: Hidradenitis suppurativa/acne inversa: criteria for diagnosis, severity assessment, classification and disease evaluation. Dermatology 2015;231:184190.

20 Revuz J: Hidradenitis suppurativa. J Eur Acad Dermatol Venereol 2009;23:985-998.
21 Sartorius K, Emtestam L, Jemec GB, Lapins J: Objective scoring of hidradenitis suppurativa reflecting the role of tobacco smoking and obesity. Br J Dermatol 2009;161:831-839.

22 Sartorius K, Lapins J, Emtestam L, Jemec GB: Suggestions for uniform outcome variables when reporting treatment effects in hidradenitis suppurativa. Br J Dermatol 2003;149: 211-213.

23 Margesson LJ, Danby FW: Hidradenitis suppurativa. Best practice and research. Clin Obstet Gynaecol 2014;28:1013-1027.

24 Kimball AB, Kerdel F, Adams D, Mrowietz U, Gelfand JM, Gniadecki R, et al: Adalimumab for the treatment of moderate to severe hidradenitis suppurativa: a parallel randomized trial. Ann Intern Med 2012;157:846-855.

25 Jemec GB: Clinical practice. Hidradenitis suppurativa. New Engl J Med 2012;366:158164.

26 Alavi A: Hidradenitis suppurativa: demystifying a chronic and debilitating disease. J Am Acad Dermatol 2015;73(5 suppl 1):S1-S2.

27 Revicki D, Willian MK, Saurat JH, Papp KA, Ortonne JP, Sexton C, et al: Impact of adalimumab treatment on health-related quality of life and other patient-reported outcomes: results from a 16-week randomized controlled trial in patients with moderate to severe plaque psoriasis. Br J Dermatol 2008; 158 : 549-557.

28 Kimball A, Okun M, Sundaram M, Mukherjee V: Patients' experiences with hidradenitis suppurativa: a qualitative study of symptoms and impacts. J Am Acad Dermatol 2013; 68:AB57.

29 Saunte DM, Boer J, Stratigos A, Szepietowski JC, Hamzavi I, Kim KH, et al: Diagnostic delay in hidradenitis suppurativa is a global problem. Br J Dermatol 2015;173:1546-1549.

30 Miller IM, Ellervik C, Vinding GR, Zarchi K, Ibler KS, Knudsen KM, et al: Association of metabolic syndrome and hidradenitis suppurativa. JAMA Dermatol 2014;150:1273-1280. 
31 Tzellos T, Zouboulis CC, Gulliver W, Cohen $\mathrm{AD}$, Wolkenstein P, Jemec GB: Cardiovascular disease risk factors in patients with hidradenitis suppurativa: a systematic review and meta-analysis of observational studies. $\mathrm{Br} \mathrm{J}$ Dermatol 2015;173:1142-1155.

32 Schrader AM, Deckers IE, van der Zee HH, Boer J, Prens EP: Hidradenitis suppurativa: a retrospective study of 846 Dutch patients to identify factors associated with disease severity. J Am Acad Dermatol 2014;71:460-467.

33 Boer J, Nazary M, Riis PT: The role of mechanical stress in hidradenitis suppurativa. Dermatol Clin 2016;34:37-43.

34 Nazary M, van der Zee HH, Prens EP, Folkerts G, Boer J: Pathogenesis and pharmacotherapy of hidradenitis suppurativa. Eur J Pharmacol 2011;672:1-8.

35 van der Zee HH, Horvath B, Jemec GB, Prens EP: The association between hidradenitis suppurativa and Crohn's disease: in search of the missing pathogenic link. J Invest Dermatol 2016;136:1747-1748.
36 Shavit E, Dreiher J, Freud T, Halevy S, Vinker $\mathrm{S}$, Cohen AD: Psychiatric comorbidities in 3,207 patients with hidradenitis suppurativa. J Eur Acad Dermatol Venereol 2015;29:371376.

37 Jemec GB, Wendelboe P: Topical clindamycin versus systemic tetracycline in the treatment of hidradenitis suppurativa. J Am Acad Dermatol 1998;39:971-974.

38 Gener G, Canoui-Poitrine F, Revuz JE, Faye O, Poli F, Gabison G, et al: Combination therapy with clindamycin and rifampicin for hidradenitis suppurativa: a series of 116 consecutive patients. Dermatology 2009;219:148-154.

39 Kimball AB, Okun MM, Williams DA, Gottlieb AB, Papp KA, Zouboulis CC, et al: Two phase 3 trials of adalimumab for hidradenitis suppurativa. New Engl J Med 2016;375:422434.
40 Boer J, Nazary M: Long-term results of acitretin therapy for hidradenitis suppurativa. Is acne inversa also a misnomer? Br J Dermatol 2011;164:170-175.

41 Alavi A: Discussion: what heals hidradenitis suppurativa: surgery, immunosuppression, or both? Plast Reconstr Surg 2016;138(suppl 3):230S-231S.

42 Gulliver W, Zouboulis CC, Prens E, Jemec GB, Tzellos T: Evidence-based approach to the treatment of hidradenitis suppurativa/ acne inversa, based on the European guidelines for hidradenitis suppurativa. Rev Endocr Metab Disord 2016;17:343-351.

43 Horvath B, Janse IC, Blok JL, Driessen RJ, Boer J, Mekkes JR, et al: Hurley staging refined: a proposal by the Dutch Hidradenitis Suppurativa Expert Group. Acta Derm Venereol 2017;97:412-413.
Clinical Practice Recommendations for Hidradenitis Suppurativa
Dermatology 2017;233:113-119

DOI: $10.1159 / 000477459$ 